\title{
Mitral Valve Disorder
}

National Cancer Institute

\section{Source}

National Cancer Institute. Mitral Valve Disorder. NCI Thesaurus. Code C78446.

A heart disorder characterized by a defect in mitral valve structure or function. 